\title{
Grafting Methyl Methacrylate onto Silk via Emulsion Graft Copolymerization Using a Diethylzinc Complex Initiator
}

\author{
C. Zhao' ${ }^{1}$ H. Okada1, M. Asakawa1, R. Sugimoto ${ }^{1 *}$, K. Yoshino² \\ ${ }^{1}$ School of Environmental Science and Engineering, Kochi University of Technology, Kochi, Japan \\ ${ }^{2}$ Shimane Institute for Industrial Technology, Matsue, Japan \\ Email: *sugimoto.ryuichi@kochi-tech.ac.jp
}

How to cite this paper: Zhao, C., Okada, H., Asakawa, M., Sugimoto, R. and Yoshino, K. (2019) Grafting Methyl Methacrylate onto Silk via Emulsion Graft Copolymerization Using a Diethylzinc Complex Initiator. Green and Sustainable Chemistry, 9, 135-142.

https://doi.org/10.4236/gsc.2019.94010

Received: September 4, 2019

Accepted: October 9, 2019

Published: October 12, 2019

Copyright $\odot 2019$ by author(s) and Scientific Research Publishing Inc. This work is licensed under the Creative Commons Attribution International License (CC BY 4.0).

http://creativecommons.org/licenses/by/4.0/ (C) (i) Open Access

\begin{abstract}
Methyl methacrylate (MMA) was grafted onto silk fiber in a one-step emulsion system using a diethylzinc and 1,10-phenanthroline complex. The reaction conditions were investigated by varying temperature and initiator to monomer ratio. Fourier transform infrared (FTIR) spectrum, thermogravimetric analysis (TGA), and scanning electron microscopy (SEC) techniques were used to characterize the structure, thermal stability, and surface morphology of the obtained product, respectively. Grafting of MMA onto silk increased the thermal stability of silk. The FTIR spectrum and SEM images provided further evidence that MMA has been successfully grafted onto the silk fiber. A peak ascribed to the $\mathrm{C}=\mathrm{O}$ stretching vibration of MMA was detected in the FTIR spectrum of grafted silk fiber, which was not present in the spectrum of pure silk fiber. Moreover, the SEM images illustrated the increase in diameter and surface roughness of grafted silk compared with pure silk. Lastly, the dyeing performance of the modified silk was significantly increased.
\end{abstract}

\section{Keywords}

Polymer Synthesis, Silk, Graft Polymerization, Emulsion, Diethylzinc

\section{Introduction}

Silk is one of the most highly sought nature fibers, which presents many excellent properties, such as high moisture absorbency, good biocompatibility, and graceful luster [1] [2]. Owing to these features, silk fibers are widely used for decorations, clothes, and other products useful for the human body [3]. However, there are some limitations to the applications of silk, which are mainly attri- 
buted to its poor crease recovery, low limiting oxygen index, easy yellowing, fibrillation, and poor color fastness [1] [4]. Therefore, finding ways to overcome these shortcomings is important for expanding the application of silk fibers. Many papers on the physical and chemical modification of silk have been published recently. Compared with other methods of modifying silk fiber, graft polymerization involves low energy consumption, leads to long-lasting modification effects, imparts excellent properties to the final product, and improves the existing properties of the parent polymer without degrading its original properties [5]. Free radical polymerization has been widely used for graft polymerization owing to its mild reaction conditions and the simplicity of the procedure. Many monomers were grafted onto silk fiber using graft polymerization, including 2-hydroxyethyl methacrylate [6], methacrylamide (MAA) [6], octafluoropentyl [7], and diethylene glycol dimethacrylate [8]. Of all vinyl monomers, MMA is the most widely used monomer for silk grafting and still represents an attractive model for studying the physicochemical and structural changes caused by grafting [9] [10].

In some of our previously published papers, we reported that diethyl (1,10-phenanthroline $\mathrm{N}^{1}, \mathrm{~N}^{10}$ ) zinc (Phen-DEZ) was used as a radical initiator for the successful graft modification of polypropylene and polyethylene [11] [12]. However, there is no literature report that has been published regarding the use of diethylzinc (DEZ) to initiate graft polymerization of silk. As the original intention of this study was to extend the applications of diethylzinc, silk was selected as graft polymerization matrix.

\section{Experimental}

\subsection{Materials}

Silk fibers from Bombyx mori silkworms were used as MMA grafting substrate after degumming and cleaning them for $12 \mathrm{~h}$ in a Soxhlet extractor using acetone and water to remove impurities. Nippon Aluminum Alkyls, Ltd. supplied DEZ. Sodium dodecyl sulfate (SDS), $\mathrm{MMA}, \mathrm{MgSO}_{4}, \mathrm{NaOH}$, hexane, chloroform, acetone, methanol, and 1,10-phenanthroline were purchased from Wako Pure Chemical Industry, Ltd. To remove the stabilizer, MMA was washed with $\mathrm{NaOH}$. Deionized water was used to prepare all solutions. Resin dye (SDN blue) was purchased from Osaka Kaseihin. Co., Ltd.

\subsection{Characterization and Measurements}

The Fourier transform infrared (FTIR) spectra of modified and unmodified silk were recorded on a Jasco FT/IR-480 Plus spectrometer, in the range of 400 $4000 \mathrm{~cm}^{-1}$. The surface morphology of silk was examined using a Hitachi SU-8020 scanning electron microscopy (SEM) instrument. Thermogravimetric analysis (TGA) of silk was carried out using a Hitachi STA7200 RV analyzer in air at the heating rate of $10^{\circ} \mathrm{C} / \mathrm{min}$. The surface morphology of silk fiber was analyzed using a Hitachi SU-8020 field emission-SEM apparatus. 


\subsection{Preparation of Phen-DEZ}

We used the same method reported in one of our previously published papers to synthesize Phen-DEZ [13]. The reaction was performed in a two-necked $50 \mathrm{~mL}$ round bottom flask equipped with a stirrer. Hexane $(20 \mathrm{~mL})$ and 1,10-phenanthroline $(1080 \mathrm{mg})$ were added to the reaction system, while slowly injecting $0.7 \mathrm{~mL} \mathrm{DEZ} \mathrm{at} 23^{\circ} \mathrm{C}$. After allowing the mixture to react for $24 \mathrm{~h}$ under argon atmosphere for protection, the mixture was filtered and the obtained Phen-DEZ was collected and dried in vacuo.

\subsection{Graft Polymerization Procedure}

Since silk fiber can be fully dispersed in water and using water as solvent presents advantages (water is a low cost, non-polluting substance), an emulsion polymerization system was selected in this study. Silk fiber (100 mg), SDS (180 $\mathrm{mg}$ ) and deionized water $(7.5 \mathrm{~mL})$ were added to a $50 \mathrm{~mL}$ flask. The excess oxygen was removed using freeze-pump-thaw cycles. Then, $2.5 \mathrm{~mL}$ MMA was added to the reaction system using a syringe. After fully mixing the reactants, the required amount of Phen-DEZ (33 mg - $500 \mathrm{mg}$ ) was added to the solution. The graft polymerization systems were maintained at the desired temperature (see Table 1) for $24 \mathrm{~h}$. The grafted silk samples were extracted using chloroform for $100 \mathrm{~h}$ to remove the homopolymer and were subsequently dried and weighted.

The grafting yield $(Y g)$ was calculated using the following equation:

$$
Y g=\left(m_{1}-m_{0}\right) / m_{0} \times 100 \%
$$

where $m_{0}$ and $m_{1}$ are the initial weight of pure silk and weight of the grafted silk, respectively.

\subsection{Dyeing}

The degummed, pure silk, and MMA-grafted silk (silk-g-MMA) were dyed using commercial resin dye (SDN blue). The ratio of dye solution to water was maintained at 1:20 according to the dyeing manual. Dyeing was performed at $60^{\circ} \mathrm{C}$ for $5 \mathrm{~min}$ and was followed by ultrasonic cleaning and washing using running water. Soap solution was used to further clean the dyed silk fiber. Lastly, both silk fibers were dried in vacuum at $23^{\circ} \mathrm{C}$, and the dried silk was directly used for color comparison.

Table 1. Graft polymerization of methyl methacrylate onto silk fiber (I:M is the initiator to monomer molar ratio).

\begin{tabular}{cccc}
\hline Entry & $\begin{array}{c}\text { Temperature } \\
\left({ }^{\circ} \mathrm{C}\right)\end{array}$ & $\begin{array}{c}\text { I:M } \\
(\text { molar ratio) }\end{array}$ & $\begin{array}{c}\text { Graft yield } \\
(\%)\end{array}$ \\
\hline 1 & 23 & $1: 15$ & 23.0 \\
2 & 23 & $1: 30$ & 97.6 \\
3 & 23 & $1: 90$ & 222.6 \\
4 & 23 & $1: 300$ & 280.8 \\
5 & 50 & $1: 300$ & 1230.6 \\
6 & 80 & $1: 300$ & 959.3 \\
\hline
\end{tabular}




\section{Results and Discussion}

By changing the reaction conditions, such as the initiator concentration and temperature, it was possible to obtain grafted silk fiber featuring different graft ratios. The results are summarized in Table 1.

As the initiator to monomer (I:M) molar ratio increased from 1:300 to $1: 15$, the graft yield decreased. When the I:M ratio increased from 1:300 and 1:90, the graft yield decreased, but remained above $200 \%$. However, when the I:M ratio was further increased to $1: 30$, the graft yield was significantly reduced to $97.6 \%$. These results suggested that within the range of I:M ratios selected in this study, increasing the amount of initiator caused the bi-radical termination of excessive radicals, and thus, caused the grafting rate to decrease.

The effect of temperature on the graft yield was more pronounced than that of the initiator concentration. When the reaction temperature was increased from $23^{\circ} \mathrm{C}$ to $50^{\circ} \mathrm{C}$ and $80^{\circ} \mathrm{C}$, the graft yield greatly increased. That could be attributed to the increase in temperature leading to more grafting sites being produced on the surface of the silk fibers, and consequently to the increase in graft yield. On the other hand, increasing the temperature also increased the rate of bi-radical termination. Therefore, when the temperature was further increased from $50^{\circ} \mathrm{C}$ to $80^{\circ} \mathrm{C}$, the graft yield decreased again.

The FTIR spectra of pure and grafted silk are shown in Figure 1. The characteristic absorption peak at $3300 \mathrm{~cm}^{-1}$ was assigned to the $\mathrm{N}-\mathrm{H}$ hydrogen bonds, and the peak at approximately $3080 \mathrm{~cm}^{-1}$ was ascribed to the $\mathrm{N}-\mathrm{H}$ stretching vibrations. The spectra for the silk samples showed absorption bands at 1653, 1543 , and $669 \mathrm{~cm}^{-1}$ (amides I, II, and V, respectively), which were assigned to the silk I structure [7] [14] [15] [16]. In comparison of the FTIR spectra of the pure and grafted silk, the characteristic peaks of poly MMA (PMMA) were only identified in the spectrum of modified silk, which demonstrated that MMA was grafted onto silk [17] [18]. In addition, the peak at $1732 \mathrm{~cm}^{-1}$ was attributed to the stretching vibrations of the ester carbonyl group, the absorption band at $2948 \mathrm{~cm}^{-1}$ corresponded to the $-\mathrm{CH}_{2}$ - groups, the weak absorbance peaks at 1632 and $1261 \mathrm{~cm}^{-1}$ were identified to be the absorbance of the C-C stretching and -C-O-C groups of PMMA, respectively, the peaks at 1193 and $752 \mathrm{~cm}^{-1}$ were associated with the $-\mathrm{CH}_{2}$ - group twisting and rocking modes, and the band at 1447 $\mathrm{cm}^{-1}$ represented the asymmetric stretching of the $-\mathrm{CH}_{3}$ groups.

Figure 2 illustrates the comparison of the TGA results for pure and grafted silk. The thermal behaviors of untreated and modified silk were quite different. The untreated silk fibers experienced a $4 \%$ weight loss at temperatures below $100^{\circ} \mathrm{C}$, while the grafted silk fibers did not exhibit significant weight loss. This occurred because the unmodified silk fibers absorbed moisture from the air, however the hygroscopicity of the grafted silk fibers was lowered by the grafted PMMA. Pyrolysis of untreated silk started at $250^{\circ} \mathrm{C}$, and when the temperature exceeded $350^{\circ} \mathrm{C}$, the weight loss rate decreased and gradually stabilized. The two thermal decomposition stages could be attributed to the cleavage of silk fiber 


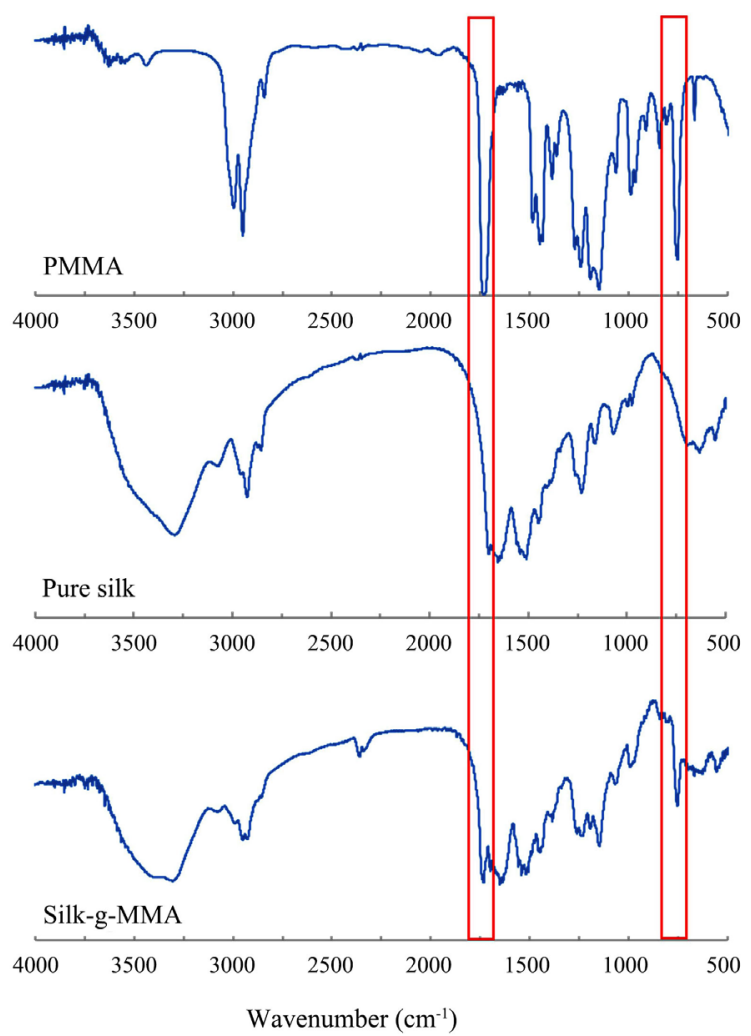

Figure 1. FTIR spectra of pure silk and PMMA and silk-g-MMA.

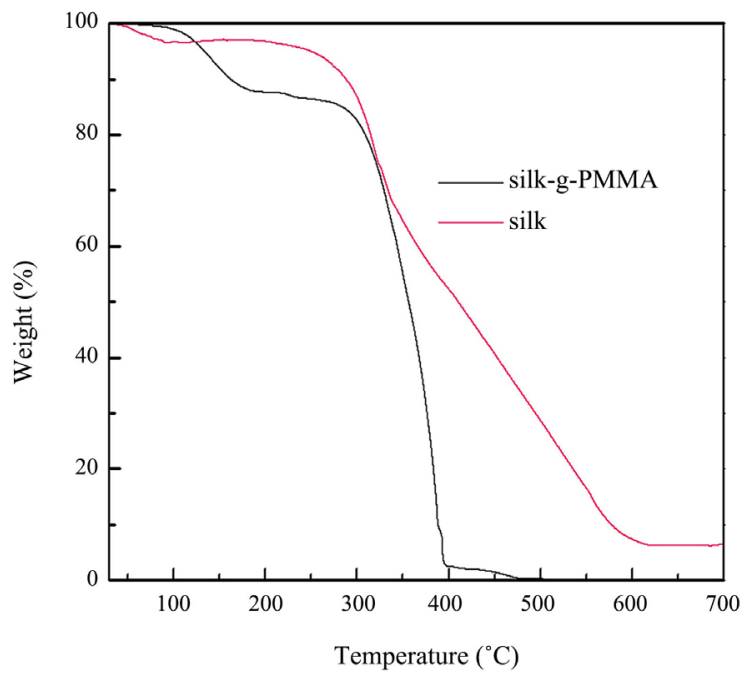

Figure 2. TGA curves for silk and silk-g-PMMA.

macromolecules and oxidation of carbon, respectively [1]. Two distinct mass loss processes can be observed in the TGA curve of silk-g-PMMA. The first weight loss stage was due to the least stable head to head linkage of grafted PMMA, which has been reported in previously published papers [19] [20]. When the temperature reached $290^{\circ} \mathrm{C}$, the grafted silk fiber underwent random scission degradation of the grafted PMMA, which began to thermally decompose. This temperature was $40^{\circ} \mathrm{C}$ higher than that of unmodified silk fiber, 
which indicated that the thermal stability of the grafted silk fiber was improved.

Figure 3 presents the surface morphology of untreated silk (a) and silk-g-PMMA (b). Pure, untreated silk presents a clean and smooth surface and no obvious sediments and texture, while silk-g-PMMA exhibits a rough and uneven appearance. This demonstrated that MMA was successfully grafted onto the silk fiber. Using the SEM images, we concluded that the diameter of the pure silk fiber was approximately $12 \mu \mathrm{m}$, while the diameter of the grafted fiber was $16 \mu \mathrm{m}$. The increase in diameter was attributed to the grafted PMMA layer, which further demonstrated the success of the graft polymerization.

Silk presents good dyeing performance, and its color is bright after dyeing. However, silk fiber exhibits poor color fastness performance and its color easily fades after washing. From Figure 4, we observed that the dyeing performance of silk fiber before and after grafting was good, and the dyed silk fiber presented brilliant blue color. Compared with the pure silk fiber, the grafted one was more easily dyed and exhibited superior dyeing performance. However, after ultrasonic washing and soaping, both silk fibers presented different degrees of fading. Comparing the fading degrees of silk fibers before and after grafting, we concluded that the silk-g-PMMA fiber exhibited better dyeing properties than pure silk, and grafting could improve the color fastness of silk fiber. This could be attributed to the grafted PMMA molecules filling in the amorphous areas of silk, which resulted in higher free volumes inside the amorphous areas [4].

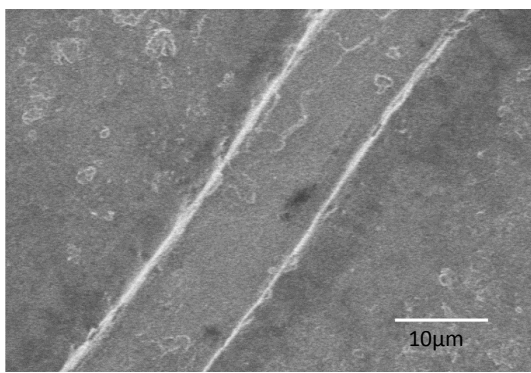

(a)

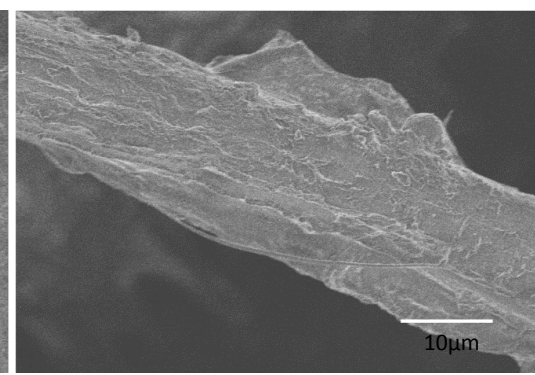

(b)

Figure 3. Scanning electron microscopy images of (a) pure silk fiber; (b) poly(methyl methacrylate)-grafted silk featuring 97.6\% weight gain.

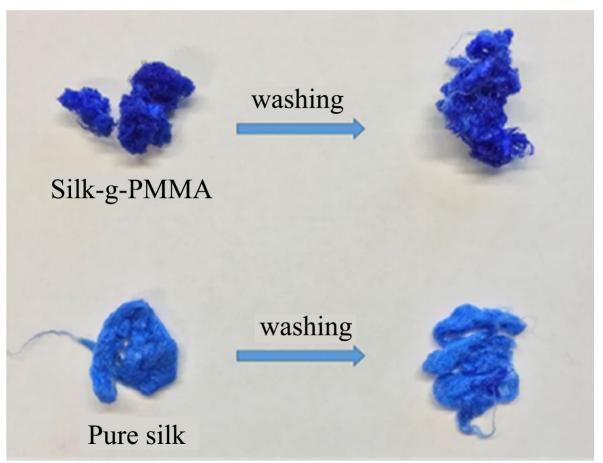

Figure 4. Dyeability of pure and poly(methyl methacrylate)-grafted silk (silk-g-PMMA). 


\section{Conclusion}

Graft polymerization of MMA onto silk fiber in an aqueous system using the Phen-DEZ complex as initiator was carried out, and the reaction presented high graft yield. The FTIR spectra confirmed the grafting of PMMA onto silk fiber. Moreover, the SEM images illustrated the changes in silk surface morphology before and after grafting. It was also found that the grafted silk presented higher thermal stability, better dyeability, as well as better color fastness than pure silk.

\section{Conflicts of Interest}

The authors declare no conflicts of interest regarding the publication of this paper.

\section{References}

[1] Liu, C., Xing, T., Wei, B. and Chen, G. (2018) Synergistic Effects and Mechanism of Modified Silica Sol Flame Retardant Systems on Silk Fabric. Materials, 11, 1842-1861. https://doi.org/10.3390/ma11101842

[2] Cheng, X.W., Guan, J.P., Yang, X.H. and Tang, R.C. (2017) Improvement of Flame Retardancy of Silk Fabric by Bio-Based Phytic Acid, Nano-TiO , and Polycarboxylic Acid. Progress in Organic Coatings, 112, 18-26. https://doi.org/10.1016/j.porgcoat.2017.06.025

[3] Guan, J. and Chen, G. (2008) Flame Resistant Modification of Silk Fabric with Vinyl Phosphate. Fibers and Polymers, 9, 438-443. https://doi.org/10.1007/s12221-008-0070-9

[4] Jutarat, P. and Watthana, K. (2006) Dyeing Properties of Bombyx mori Silks Grafted with Methyl Methacrylate and Methacrylamide. Journal of Applied Polymer Science, 100, 1169-1175. https://doi.org/10.1002/app.23216

[5] Prachayawarakorn, J. and Boonsawat, K. (2007) Physical, Chemical, and Dyeing Properties of Bombyx mori Silks Grafted by 2-Hydroxyethyl Methacrylate and Methyl Methacrylate. Journal of Applied Polymer Science, 106, 1526-1534. https://doi.org/10.1002/app.26586

[6] Basri, M., Harun, A., Ahmad, M.B., Razak, C.N.A. and Salleh, A.B. (2001) Immobilization of Lipase on poly(N-vinyl-2-pyrrolidone-co-styrene) Hydrogel. Journal of Applied Polymer Science, 82, 1404-1409. https://doi.org/10.1002/app.1977

[7] Li, Z., Jin, F., Cao, B. and Wang, X. (2008) Modification of Silk Fibers via Emulsion Graft Copolymerization with Fluoroacrylate. Chinese Journal of Polymer Science, 26, 353-362. https://doi.org/10.1142/S025676790800300X

[8] Chen, G., Guan, J., Xing, T. and Zhou, X. (2006) Properties of Silk Fibers Modified with Diethylene Glycol Dimethacrylate. Journal of Applied Polymer Science, 102, 424-428. https://doi.org/10.1002/app.24064

[9] Das, A., Saikia, C.N. and Hussain, S. (2001) Grafting of Methyl Methacrylate (MMA) onto Antheraea assama Silk Fiber. Journal of Applied Polymer Science, 81, 2633-2641. https://doi.org/10.1002/app.1707

[10] Masuhiro, T., Nobutami, K. and Giuliano, F. (1993) Structural Analysis of Methyl Methacrylate-Grafted Silk Fibers. Journal of Applied Polymer Science, 50, 885-890. https://doi.org/10.1002/app.1993.070500516

[11] Zhao, C., Okada, H. and Sugimoto, R. (2018) Diethyl(1,10-phenanthroline- $\mathrm{N}^{1}$, 
$\mathrm{N}^{10}$ )zinc Initiated Grafting of Styrene on Polypropylene/Polyethylene. Bulletin of the Chemical Society of Japan, 91, 1576-1578. https://doi.org/10.1246/bcsj.20180188

[12] Zhao, C., Okada, H. and Sugimoto, R. (2018) Surface Modification of Polypropylene with Poly(methyl methacrylate) Initiated by a Diethylzinc and 1,10-Phenanthroline Complex. Reactive and Functional Polymers, 132, 127-132. https://doi.org/10.1016/j.reactfunctpolym.2018.09.012

[13] Zhao, C., Okada, H. and Sugimoto, R. (2018) Polymerization of Styrene in Aqueous System Using a Diethylzinc and 1,10-Phenanthroline Complex. Polymer, 154, 211-217. https://doi.org/10.1016/j.polymer.2018.09.019

[14] Liu, Y., Qian, J., Liu, H., Zhang, X., Deng, J. and Yu, T. (1996) Blend Membrane of Regenerated Silk Fibroin, Poly(vinyl alcohol), and Peroxidase and Its Application to a Ferrocene-Mediating Hydrogen Peroxide Sensor. Journal of Applied Polymer Science, 61, 641-647. https://doi.org/10.1002/(SICI)1097-4628(19960725)61:4<641::AID-APP7>3.0.CO;2$\underline{\mathrm{L}}$

[15] Qian, J., Liu, Y., Liu, H., Yu, T. and Deng, J. (1996) An Amperometric New Methylene Blue N-Mediating Sensor for Hydrogen Peroxide Based on Regenerated Silk Fibroin as an Immobilization Matrix for Peroxidase. Analytical Biochemistry, 236, 208-214. https://doi.org/10.1006/abio.1996.0158

[16] Hu, Y., Zhang, Q., You, R., Wang, L. and Li, M. (2012) The Relationship between Secondary Structure and Biodegradation Behavior of Silk Fibroin Scaffolds. Advances in Materials Science and Engineering, 2012, Article ID: 185905. https://doi.org/10.1155/2012/185905

[17] Shang, S., Zhu, L., Chen, W., Yi, L., Qi, D. and Yang, L. (2009) Reducing Silk Fibrillation through MMA Graft Method. Fibers and Polymers, 10, 807-812. https://doi.org/10.1007/s12221-009-0807-0

[18] Thakur, V.K., Vennerberg, D., Madbouly, S.A. and Kessler, M.R. (2014) Bio-Inspired Green Surface Functionalization of PMMA for Multifunctional Capacitors. RSC Advances, 4, 6677-6684. https://doi.org/10.1039/c3ra46592f

[19] Diego, L., Nogueira, M.F.J. and Elaine, M.S. (2013) Thermal Evaluation of Cashew Nutshell Liquid as New Bioadditives for Poly(methyl methacrylate). Journal of Thermal Analysis and Calorimetry, 111, 619-626. https://doi.org/10.1007/s10973-012-2383-6

[20] Takashi, K., Atsushi, I., Brown, J.E., Koichi, H., Tatsuki, K. and Eiji, M. (1986) Effects of Weak Linkages on the Thermal and Oxidative Degradation of Poly(methyl methacrylates). Macromolecules, 19, 2160-2168.

https://doi.org/10.1021/ma00162a010 